\title{
Evaluating the implementation of health checks for adults with intellectual and developmental disabilities in primary care: The importance of organizational context
}

\begin{abstract}
Compared to other adults, those with intellectual and developmental disabilities have more health issues, yet are less likely to receive preventative care. One strategy that has shown success in increasing prevention activities and early detection of illness is the periodic comprehensive health assessment (the 'health check'). Effectively moving evidence into practice is a complex process that often receives inadequate attention. This qualitative study evaluates the implementation of the health check at two primary care clinics in [Removed for review] and the influence of the clinic context on implementation decisions. Each site implemented the same core components, however, due to contextual differences, some components were operationalized differently. Adapting to the setting context is important to ensuring successful and sustainable implementation.

Keywords: primary care, developmental disability, health check, implementation
\end{abstract}

\section{Introduction}

Compared to other adults, those with intellectual and developmental disabilities (IDD) have more health issues (e.g., higher rates of epilepsy, mental ill health, hearing and sight problems, diabetes, and disorders of the respiratory, gastro-intestinal and endocrine systems) (Buszewicz et al., 2014; Chauhan, Kontopantelis, Campbell, Jarrett, \& Lester, 2010; Robertson, Hatton, Emerson, \& Baines, 2014; Sullivan et al., 2011). Primary care and family or general practice (subsequently referred to in this article as “primary care”), with its focus on delivering 
comprehensive, patient-centered and proactive care is ideally positioned to achieve better prevention and management of the health problems of adults with IDD. However, such care is generally reactive, responding to problems raised by patients with IDD, rather than proactive, to support earlier identification and management of disease. A number of studies show lower than expected rates for proactive health screening, prevention and promotion activities (Buszewicz et al., 2014; Chauhan et al., 2010; Lennox et al., 2007; Ouellette Kuntz et al., 2014).

There is a growing body of evidence on the benefit of the periodic comprehensive health assessment (the 'health check') for persons with IDD. Performance of the health check is associated with increased prevention activities (e.g., immunizations, cancer screening), increased detection of disease (thyroid and gastrointestinal disease, psychiatric disorder), increased detection of other conditions (dental problems, skin conditions), and improved follow-up management (Buszewicz et al., 2014; Robertson et al., 2014). Health checks can also enhance practitioner knowledge of the health needs of people with IDD, and may help to identify gaps in health services (Lennox et al., 2013; Robertson et al., 2014).

The Canadian Consensus Guidelines for the Primary Care of Adults with Developmental Disabilities begin with a recommendation to "conduct the annual comprehensive preventive care assessment including physical exam” (Sullivan et al., 2011, p. 544). In some jurisdictions (e.g., UK and Australia), funding or other policy incentives have been offered for delivery of the health check, with subsequent increases in rates of delivery (Buszewicz et al., 2014; Lennox et al., 2013). In [Removed for review], policy incentives are not in place and a recent provincial study of primary care showed that health check rates and other preventive actions are lower for those with IDD than for the general population (Ouellette-Kuntz, Cobigo, Balogh, Wilton, \& Lunsky, 2015). 
Effectively moving guideline evidence into practice is a complex process and many theories have been published on factors that can promote or inhibit effective and sustainable implementation (Damschroder et al., 2009). Broadly speaking these address the nature of the intervention (i.e., complexity, cost, evidence of effectiveness), the implementation approach (i.e., the constellation of processes to get an intervention into use within an organization) and the context (i.e., factors internal and external to an organization that influence implementation such as leadership, resources, learning climate, health policy) (Damschroder et al., 2009; RycroftMalone 2008). Attending to context is important because implementation is more likely to be successful and sustained if the new practice fits well with a setting's mission, resources and current processes (Proctor et al., 2010). However, the role of context in implementation is typically not well described (Kirsh, Lawrence, \& Aron, 2008; Rycroft-Malone, 2008).

Previous health check research has not directly studied the implementation process but has sought feedback from patients and physicians about the experience, including challenges encountered. For the primary care organization, these challenges included identifying eligible individuals and organizing the visit. For the clinician, these challenges included limited experience working with people with IDD, lack of needed information (clinical, community resources), and the longer time required to accomplish the assessment given the frequency of comorbidities and communication issues. For persons with IDD, these challenges included anxiety about the visit and reluctance to participate (Buszewiez et al., 2014; Lennox et al., 2013; Robertson et al., 2014; Walmsley, 2011). As a result, even when jurisdictions have provided funding incentives to perform the health check, the rate of delivery is still variable (Lennox et al., 2013; Walmsley, 2011). A more systematic examination of the implementation process, including the role of context, is critical to improve uptake and inform policy. This type of 
research complements existing studies on patient outcomes. Both are important to move innovations into practice. Otherwise, if a new practice implementation fails, reasons will be unclear and there may be reluctance to make significant future investments.

Similar to other jurisdictions, there is interest in implementing the health check in [Removed for review], Canada. Building on work done elsewhere and evidence from implementation science research, our research team took on two roles. First, drawing on active implementation frameworks, we supported a staged, facilitated implementation process to incorporate the health check into primary care practice. Second, we evaluated the implementation - both the process (e.g., what was done) and the outcomes (e.g., the quality of health check delivery). While the research team supported both the implementation and the evaluation, the functions were separated and the evaluators on the team did not deliver implementation support.

The focus of the present paper is the process evaluation. Study aims are to describe the practice changes made to implement the health check, and to evaluate how the practice context affected the implementation decisions. An implementation outcomes evaluation (e.g., number of health checks completed, quality of health exam, staff changes in knowledge and attitudes) is underway and will be reported in a separate paper.

This research can add to the growing literature on how to implement organizational level interventions, and the conditions that influence implementation. To our knowledge, this is the first time that implementation of a new program for individuals with IDD in primary healthcare has been studied. Our team is conducting a parallel implementation evaluation of organizational changes to improve emergency healthcare for patients with IDD (Authors, YYYY).

\section{Methods}




\section{Primary care settings}

In [Removed for review], as in all Canadian jurisdictions, physician care is covered by publically funded universal health insurance. Primary care reform has been underway for more than a decade and delivery has shifted away from fee-for-service to other reimbursement models that include varying blends of capitation, fee-for-service and incentive payments to expand patient enrolment and improve quality of care (Rosser, Colwill, Kasperski, \& Wilson, 2011). Among the newer models is the Family Health Team (FHT), akin to the patient-centered medical home model in the US. The FHT is an inter-professional team model that includes some additional funding to support care for patients with chronic and complex healthcare needs such as those with IDD. Teams can apply for salary funding for non-physician professionals (such as nurse practitioners, social workers, pharmacists) and receive support for an electronic medical record system, including analytic staff. Quality management is a priority and each team is expected to use EMR data for auditing performance and quality improvement. Some incentives are in place for preventive care but none are specific to patients with IDD. About 25\% (2700) of [Removed for review] family physicians work in the FHT model and most [Removed for review] academic family medicine practices are FHTs (Family Medicine Report, 2013; Rosser et al., 2011; Russell et al., 2009).

This study included two FHT primary care clinics. FHT 1 is a large practice located in a major urban center, with 70 staff physicians, 35,000 rostered patients, and 5 clinic locations. FHT 2 is a smaller practice located in a mid-urban center, with 25 staff physicians, 15,000 rostered patients and one clinical site. Both practices include diverse allied health staff and both are practice sites for academic family medicine programs. A third FHT was included in the study 
but withdrew prior to implementation for reasons which will be discussed in the separate paper focused on outcomes.

\section{Health Check Intervention}

The Canadian Guidelines (Sullivan et al., 2011) recommend that an annual comprehensive preventive care assessment be performed, and provide a detailed list of evidencebased recommendations and modifications for managing the health of adults with IDD (Sullivan et al., 2011). The recommendations are wide-ranging. In addition to a detailed list of physical and mental health preventive care maneuvers to perform, they address provider-patient communication and the role of interprofessional care. A companion document of clinical tools was developed and mailed to all Canadian family physicians and posted online (Developmental Disabilities Primary Care Initiative, 2011).

Guidelines are not necessarily a product ready to be used in practice (Pronovost, 2013; Rycroft-Malone, 2008). Although comprehensive in their clinical content, neither the 2011 Canadian Consensus Guidelines nor the accompanying clinical tools specified a process to follow for the health check implementation. An early task for the study research team and primary care leads was to collaboratively identify the core components of the health check, building on their expertise and experiences of other jurisdictions. These components included:

1. Identification of patients with IDD: Prior to offering the health check, practice patients first need to be identified as having such disabilities and as being appropriate for the intervention.

2. Proactive invitation for health check visit: Patients with IDD need to be invited to visit the clinic as the health check is intended to be initiated by the health are practitioner rather than by the patient or caregiver because of a current symptom. 
3. Staff education and training: Staff need to understand the reasons for the health check, their role, and key information about developmental disabilities in accordance with the guidelines.

4. Delivery of the health check in alignment with the guidelines: Some key elements include:

- $\quad$ Screening for conditions more prevalent in those with IDD (e.g., vision, dental, obesity);

- Adapting communication to increase the comfort and participation of the person with

IDD (and their caregiver), and to obtain relevant history and other information;

- Using an inter-professional team approach, possibly over a series of visits.

\section{Implementation Process}

Practice change requires active planning and support to shift from a "let it happen”' to a “make it happen” approach (Greenhalgh, Robert, Macfarlane, Bate, \& Kyriakidou, 2004). Facilitation can keep the implementation momentum going and help overcome barriers to a successful adaptation of a new practice (Fortney et al., 2012). Our facilitation strategy relied on a partnership between the central research team and local site staff based on the premise that, while external support can be valuable, an organization's own health care staff are best positioned to add credibility, engage site staff and identify and make required adaptations (Fortney et al., 2012). In our study a senior physician served as the practice change lead at each site and actively contributed to the change process. Additionally, a small amount of study funding paid for dedicated facilitator support at each site. The central research team contributed knowledge of the health check evidence, helped develop training and clinical tools tailored to the needs of each site, held regular meetings with the site team for updates and problem solving, and periodically convened joint meetings between the two FHT sites to share experiences and problem solve.

Implementation followed a staged change process developed by the National Implementation Research Network (Blase, \& Fixsen, 2013) and included: 
- Exploration: Create organizational awareness of the health check practice and its benefit, engage staff and learn about clinic contextual features that might affect implementation.

- Installation: Plan and implement the required changes (e.g., work procedures, staff roles, EMR functions, creation/customization of tools/resources, training and supervision).

- Initial Implementation: Begin delivery of the health check, and collect feedback to refine and improve the process.

- Full 'sustainable’ implementation: Consider processes and procedures required to embed the health check as ongoing standard practice.

\section{Data sources}

Implementation log: A semi-structured template was used to record information on each site’s progress in implementing the health check across the four implementation stages (Blase, \& Fixsen, 2013), along with helping and hindering factors. The log addressed the four stages, with questions and prompts within each stage based on evidence about implementation barriers and facilitators (Damschroder et al., 2009; Fortney et al., 2012; Stein, Celedonia, Kogan, Swartz, \& Frank, 2013; Torrey, Bond, McHugo, \& Swain, 2012). For each site, the log was completed twice (at the midpoint and end of the study) by the research team evaluation coordinator based on an interview with the site facilitator and other site staff as needed. The same coordinator conducted all interviews to maximize consistency/reliability.

Staff focus groups: At the end of the study, the research team conducted a focus group at each FHT site where individuals who had an active role in the implementation were invited to reflect on the implementation process. Across the two sites, eight individuals participated including physicians (4), clerical staff (1), quality manager (1) and site implementation facilitators (2), A semi-structured guide was used to facilitate discussion. Topics included: value 
added (if any) of the facilitated implementation process, barriers and facilitators encountered during implementation, and strategies in place or planned to support continued use. The focus group discussions lasted about an hour, and were digitally recorded and transcribed verbatim.

Intervention template: For each of the core components of the health check, the site facilitator documented the individuals responsible for the implementation (who), the process (what), the point in the care delivery process (when), and any tools used to support delivery. The form was completed at the midpoint of the study and updated at the end to describe any adaptations that had occurred and reasons for the adaptation.

\section{Analysis}

The evaluators conducted a qualitative analysis of data sources to develop descriptions, per FHT site, of the health check implementation and to assess the influence of context on implementation decisions. The analysis used a deductive approach (Burnard, Gill, Stewart, Treasure, \& Chadwick, 2008; Elo, \& Kynga s, 2008; Kirsh et al., 2008), guided by two a priori frameworks - the health check components defined by the central research and primary care site teams (described earlier in the paper), and contextual features of the FHT model expected to influence implementation. The latter framework included organizational features that are expected to affect primary healthcare delivery and quality in general (Aggarwal \& Hutchison, 2012), but are also defining features of the FHT model (Russell, 2009). The features included:

- $\quad$ Practice size and structure (e.g., staff size, patient load, number of practice sites, rurality): Larger practices with multiple sites may need more time to introduce new processes and decision making may be more complex (Conference Board, 2014)

- Inter-professional team (e.g., presence of non-physician health professionals such as nurse practitioners, social workers, pharmacists and dieticians): Inter-professional teams provide a 
range of services and can enhance clinic capacity to provide comprehensive, integrated care (e.g., promotion, prevention and intervention). Team care is also associated with improved patient experience (Conference Board, 2014; Russell, 2009; Aggarwal \& Hutchison, 2012).

- EMR functionality (e.g., electronic health record, electronic alerts to prompt preventive care actions (e.g., diabetes foot checks) and quality checks (e.g., for drug interactions), electronic clinical information and support tools at the point-of-care): EMR functionality can enhance service delivery by supporting evidence-informed clinical decision making, proactive prevention and disease management, care coordination and quality monitoring (Conference Board, 2014; Russell, 2009; Ketchum, 2011; Aggarwal \& Hutchison, 2012).

- Quality improvement program (e.g., annual reporting on a documented set of quality commitments, both self-selected and externally directed): Systematic quality monitoring (data collection, feedback and follow-up) encourages goal setting and use of feedback to monitor and modify practice (Health Quality Council, 2014; Aggarwal, 2012).

- Academic affiliation (e.g., training and research roles): Academic practices can involve trainees in new models of care, and actively engage in research and evaluation to advance learning and wider sharing. A learning climate may be present, which is associated with more successful implementation of new practices (Bitton, 2010; Damschroder, 2009).

In addition to these features, we remained open to new themes arising from the data.

Two evaluators independently reviewed the three data sources and coded references to the implementation process that pertained to the two a priori frameworks - the health check components and contextual features of the FHT model. The evaluators also coded references to contextual features not captured by the framework. Triangulating across the three sources and guided by the framework domains, the evaluators combined the codes into common groupings 
and, through an iterative process and discussion, reached consensus on higher level themes (Patton, 2002). Member checking occurred at a follow-up meeting with the lead physician and facilitator from each site, where the evaluators led a structured discussion to validate the results.

Research ethics board approval for the study was received from the home institution of the research team and the academic institutions of the participating primary care clinics.

\section{Results}

\section{Site context}

Beyond the framework domains, the practice focus emerged as a relevant contextual factor. Practice foci are specific interest areas - usually related to a patient demographic group or health condition - where the practice holds deeper expertise, has developed specific care protocols, provides enhanced training, etc. Related to the health check implementation, the extent to which care of individuals with IDD was a practice focus emerged as a relevant influence.

Table 1 compares the two study FHTs by contextual domain. FHT 1 is a large academic practice with staff dispersed across multiple clinical locations that vary somewhat in clinical team staffing and operations. The EMR system is an important support for evidence based practice delivery and for standardizing care across multiple locations. The team is one of 12 training sites for the Department of Family Medicine. Care of people with IDD is not a focus but does align with the practice-wide mandate of caring for vulnerable populations such as immigrants, homeless, and people living with HIV. The site quality improvement (QI) program did not include the health check initiative so obtaining staff time for the installation (e.g., to identify practice patients with IDD, adapt EMR tools) was a challenge. The study physician lead did not have protected time through QI or academic roles to support the implementation. 
FHT 2 is a smaller academic practice with all care delivered out of one clinical location. The EMR system includes a fillable form for client information but is not routinely used for more advanced functionality (e.g., alerts, point-of-care clinical information). FHT 2 is the main teaching practice for the Department of Family Medicine where care of adults with IDD is a longstanding interest, and several FHT physicians have advanced training and expertise in caring for persons with IDD. At the start of the study, the practice QI program did not include the health check intervention and there were no QI supports available to facilitate implementation. However, the lead physician has some remunerated academic time to focus on this work and there was a small amount of additional funding for a research assistant.

\section{Health Check Implementation and Contextual Influences}

Table 2 describes how the health check was implemented at each site and how contextual factors influenced implementation.

\section{Identification of patients with IDD}

While neither had an IDD patient registry, both sites used their EMR systems to identify a preliminary list of eligible patients. FHT 2 did this through a diagnostic code search whereas FHT 1 used a keyword search for diagnostic and selected other terms such as 'special education' and the names of local group homes. At both sites, the patient list was reviewed by medical and nursing staff to verify inclusion. Finding the time for the EMR search, staff review and required coordination was time consuming for both sites but particularly so for FHT 1, as the keyword search needed to be developed and staff were dispersed across multiple locations.

\section{Proactive invitation for health check visit.}

Both practices initially planned to have all administrative staff participate in the proactive phone invitation but ultimately centralized the task to one designated staff. Recognizing that 
patients might not identify as having an IDD or find the invitation confusing, both sites created a standardized invitation script, with options for tailoring the content to the abilities of the individual or their caregiver. Centralizing the call to one person simplified the process and allowed the task to be assigned to an administrative person with the skills and comfort to adapt the call process, but it also concentrated the time demands on one person.

At FHT 1, a single clerk located in one clinic made all the calls and then linked the patient to a different clerk at the patient's local clinic to make the booking. At FHT 2, the same clerk completed both the phone invitation and the appointment booking. Both sites made reminder phone calls to the patient ahead of the appointment (two calls by FHT 1 and one call by FHT 2), and both alerted the physician to the visit on the day of the appointment. This was achieved at FHT1 through an alert automatically generated from the EMR and at FHT2 through an email note from booking clerk.

For both sites proactive outreach was not a routine task and both needed to obtain clerical time to perform this function. This was particularly difficult at FHT 1 where competition for resources was high and caring for patients with IDD was not a specific priority.

Staff education and training. Staff education and training served two purposes - to orient site staff to the project (offered during the exploration and installation stages), and to prepare/support staff to deliver the health check and effectively work with persons with IDD.

Regarding orientation, at both sites the lead physician and facilitator attended staff meetings to introduce the health check initiative and provide information about the needs of patients with IDD and adapted care approaches. At FHT 1, this work was done on a volunteer basis by the lead physician. Finding time to coordinate and prepare for presentations was a challenge, as was getting adequate agenda time at meetings. At FHT 2, the lead physician 
attended staff meetings and also delivered rounds to residents, physicians and allied health staff. This more in-depth education activity was facilitated by the availability of remunerated academic time for the physician lead, his expertise and the site focus on care of patients with IDD.

There were site differences in how staff were supported to deliver the health check. At FHT 1, EMR-based point-of-care tools were commonly used to reach staff spread across multiple locations. An IDD specific preventative care fillable form, already embedded in the EMR, was expanded to include prompts and links to additional information and tools. Some tools were from the [Removed for review] DD Primary Care Initiative toolkit (e.g., health watch tables). Others were developed during the study based on staff needs identified during the exploration and installation phases (e.g., list of local IDD-friendly health and social service providers; financial information customized for patients, caregivers and staff; screening tool; communication aid for follow-up).

FHT 2 offered support through a half day curriculum enhancement targeted specifically to residents on care of adults with IDD. The resident focus was possible in part because FHT 2, as the main teaching site for the family medicine clinical experience, had some influence over the curriculum. Furthermore, there was considerable expertise in IDD along with protected time among some FHT physicians to provide training. Regarding EMR tools, the practice had a fillable form which referenced other web based tools and resources for care of adults with IDD, but these could not be accessed directly from the EMR.

Delivery of the health check in alignment with the consensus guidelines. The practices differed in how they delivered the health check exam (Table 2). At FHT 1, the health check was primarily completed by staff physicians, with variable participation by residents and nurse practitioners equivalent to any other patient population. At FHT 2, all health checks were 
to be completed by residents under the supervision of their clinical teachers during their first year core Family Medicine clinical experiences.

Both sites initially planned the health check delivery via two consecutive appointments first with a nurse or nurse practitioner to obtain medical history and then with the physician or resident for the physical exam. However, neither used this approach which was complicated to schedule and placed more burden on the patient who might not return for the second visit.

Although an inter-professional approach was recommended by the Canadian Guidelines (Sullivan et al., 2011), it was challenging to systematically implement at both sites, and is an area where FHTs are generally still developing work processes. Scheduling was complicated by not knowing which allied health staff were needed until after the appointment. Also, there was concern that longer appointments or a second appointment would be challenging for the patient.

\section{Discussion}

Walmsley (2011) described the annual health check as 'probably the single most important investment in the primary healthcare of people with intellectual disabilities of the $21^{\text {st }}$ century’ (p. 165). In Canada, the release of the Guidelines for Primary Care of Adults with IDD (2011), including a recommendation for the health check, has provided an important opportunity and foundation for improving quality of primary care for patients with IDD. The present study compared how health check implementation was carried out in two FHT clinics, and examined the influence of selected organizational contextual factors on implementation. Such work is important because, if others want to implement the intervention, they need to know how it might fit within their setting (Ovretveit, 2014).

\section{Contextual influences}


Overall the study showed that, while both sites were FHT organizations, they had different capabilities and work processes which influenced their implementation approach. Among the assessed factors, the extent to which caring for patients with IDD was a practice focus appeared to have a major facilitating role. For example, decisions by FHT 2 to use remunerated academic time for implementation of the health check, to leverage their role as the main practice site in their academic program to provide more extensive training on IDD, and to engage residents in health check delivery, were likely facilitated by the site focus on patients with IDD. Additionally, while the health check was not in the organization's QI program at first, some clerical and technical support was made available for the implementation, and the health check became part of the QI program toward the end of the study. In contrast, at FHT 1, care for patients with IDD was not a specific focus. The implementation of the health check was more complicated due to the practice having multiple clinical sites and there were fewer supports available for implementation. The robust EMR system was a key implementation resource and eventually a modest amount of clerical and IT time was obtained to help the process, possibly due to the practice's general interest in serving vulnerable populations and high practice regard for the physician implementation lead on the study. Still the implementation was more challenging at FHT 1.

The importance of practice focus has been noted in other implementation studies (Damschroder, 2009). Torrey (2012) and Bond (2012) assessed factors associated with successful implementation of five evidence based practices for community mental health care. Organizational prioritization (e.g., supportive attitude, understanding, mandate) emerged as an important facilitating factor for both initial implementation and for practice sustainability. Torrey (2012) noted that prioritization may be particularly important when a new practice is perceived 
as a more uncommon implementation choice. This may be the case for a smaller patient group such as those with IDD.

\section{Implementation strategies}

Beyond prioritization, each clinic built on its strengths and capacities to achieve the practice change, and tailored the implementation approach to their setting. Their approaches included some commonalities (e.g., both used a scripted outreach call) but also some differences (e.g., at FHT 1 the robust EMR system was the main driver; at FHT 2 resident participation was key). Both sites are reflecting on their experiences and exploring next steps. Implementation outcome data will further inform their understanding of what worked well and where refinement is needed. Continued efforts of trialing and learning are particularly important given the limited currently available evidence on how to effectively implement health checks.

Pertaining to identification, both practices used their existing EMRs to identify eligible patients. However, how IDD was recorded in charts was variable and the two stage process (EMR search and manual review) was labor intensive. Developing an effective identification process is key to the implementation of any new practice (Stein et al., 2013) but is particularly challenging for delivering the health check if there is no trusted infrastructure to identify and track patients with IDD. In [Removed for review] there is no system level IDD registry and recent provincial research has shown that healthcare records often do not identify individuals with IDD (Lunsky, Klein-Geltink, \&Yates, 2013). Even in the UK, where an outside patient registry exists and primary care practices receive funding to conduct the health check, agreement on identification of appropriate patients is still a challenge. There is concern that individuals with less significant disabilities are missed, and local practices often have their own lists that they need to reconcile with the external registry (Buszewicz et al., 2014; Walmsley, 2011). 
Both study sites are now considering how to enhance staff recognition of individuals with IDD and standardize EMR documentation in order to more consistently and efficiently identify eligible patients. Both sites have a list of patients with IDD based on the initial search but need to ensure that the list is continually updated. This process is challenged by the infrequent documentation of IDD in the patient chart, inconsistent use of terminology and codes when it is documented, and physician reluctance to identify patients as IDD who have not received a formal diagnosis, which can take years to acquire. FHT 2 is standardizing EMR diagnostic coding for presence of IDD, and the code will become the automatic identifier in their QI program to flag health check eligibility. FHT 1 is exploring how to resolve this issue.

Pertaining to the invitation, both sites have centralized the invitational call to one individual and developed a script to guide the process. In other jurisdictions visit uptake has been a challenge, with varied participation rates (10-100\%) reported (Buszewicz et al., 2014; Robertson et al., 2014; Walmsley, 2011). For patients with IDD, an invitation to see the doctor can be frightening or confusing, leading to appointments being avoided or missed (Robertson et al., 2014). Buszewicz (2014) found that younger patients living in deprived neighborhoods were less likely to attend than other patients with IDD when they received a call.

Strategies recommended in the literature to increase attendance include reminder calls and careful communication (Robertson et al., 2014), both of which were used in the present study. Our research team is now examining differences in demographics of invited persons who do and do not receive the health check, to assess systematic biases in attendance. From a sustainability perspective, protecting staff time to make the calls is needed as well as building an automatic process into the EMR to prompt staff when a patient is due for a health check. Feedback from patients on the invitation process is also needed. 
Pertaining to training and education, the sites used different strategies including presentations to staff, EMR supports, and enhancements to the resident curriculum. How clinicians are educated about the health check varies by jurisdiction and research on the success of different strategies is lacking. In the Australian health check program, family physicians did not receive specific training but were provided with a comprehensive booklet to guide the assessment (Lennox et al., 2007; Lennox et al., 2013). In parts of the UK, physicians need to attend a local training to be eligible for funding incentives (Walmsley, 2011). It is important to explore which training approaches lead to greater success. For example, in [Removed for review], it was found that the combination of in-person and internet based case based learning led to greater changes in primary care provider knowledge, attitudes and comfort than simple provision of written guidelines and clinical tools (Balogh et al., 2015). Our study is collecting staff feedback about adequacy of preparation as well as reviewing chart data to learn more about the quality of the health check exam to gain insight into the success of the varied training approaches. From an implementation success perspective, it is important to choose training approaches that fit with site resources and minimize burden in busy schedules.

Pertaining to intervention delivery, each site built upon available resources and opportunities. We are in the process of reviewing charts to learn more about the health actions taken as part of the process and whether there has been an increase over past practice. We are also surveying clinical staff about their experience, including any adaptations to care that they made, perceived knowledge and skills, and feasibility/time requirements. FHT 1 has a particular interest in improving the value and use of EMR tools. Whether and how nurse practitioners and other allied staff can be more involved is a potential issue to explore at both sites.

\section{Sustainability and spread}


Both sites are now considering what is needed for health check sustainability. At FHT 2 the health check has become part of the QI program, and the current aim is that $75 \%$ of those recognized with IDD have a health check within an 18 month period. A chart review is nearing completion and could become a routine quality feedback strategy. Continuation at FHT 1 after the study ends is less certain. The QI program agenda is busy and patients with IDD are not a practice wide priority. However, pockets of expertise and interest among senior staff physicians may provide some momentum, and integration into residency education is being explored.

Beyond these site specific considerations for enhancing implementation, there is a larger system level question about the feasibility of health check spread to other primary care practices. The FHT practices participating in this study had resources and opportunities to leverage that may not be available in other primary care clinics (e.g., EMR functionality, QI program). Also, the facilitated staged implementation approach provided important momentum and practical assistance (e.g., tailored tools) and will not necessarily be available to other sites. Finally, having an organizational focus on care of patients with IDD emerged as an important implementation facilitator, and may not to be present in other primary care organizations.

Further thought is required on how to support wider implementation under more typical conditions. Provincial policy levers may help (e.g., funding incentives, accountability reporting requirements), ideally combined with opportunities to obtain tailored on-site supports. However, as other jurisdictions have found (Lennox et al., 2013; McConkey et al., 2015), practice uptake will vary, even with incentives. Walmsley (2011) raised the idea of developing specialized practices that can serve as area hubs and primary sources of care. Another option is to work with selected physicians within a practice who have a special interest in care of patients with IDD. Such an approach might reach more practices but organizational supports (e.g., to identify and 
invite patients to the health check) will still be needed. McConkey et al. (2015) outlined an approach used in Ireland where local learning disability nurses worked with primary care practices to identify patients with IDD and encourage their attendance for health checks. The question of how to enhance primary care capacity to meet the needs of patients with IDD is an important one that requires further investigation and consideration of the local context.

\section{Limitations}

The study has a number of limitations. Feedback was obtained from a limited number of site informants and some perspectives on examined issues may have been missed. Additionally, the working relationship between the research team and local implementers could have introduced bias in the data collection and analysis, although the evaluators did not participate in the implementation activities. Pertaining to the setting, only two practice sites operating within a specific primary care model (the Family Health Team) were examined. Further study of other

primary care practice sites and models can assess the broader applicability of results and identify additional factors that can affect health check implementation. Also important to note is that the implementation findings have not yet been integrated with outcome results. Leveraging contextual opportunities may enhance feasibility of implementation but outcome data are needed to inform understanding of what was implemented, the quality of the implementation, the impact on staff and service users, and to provide direction in terms of where implementation improvement is needed. The study did not examine implementation costs and this would be an important consideration when determining feasibility.

\section{Conclusion}

Poor health and healthcare have been a concern for individuals with IDD for some time, but strategies to address these problems have been lacking. Now there is a strong evidence-base 
on the benefit of the health check. However, to change practice successfully across jurisdictions, the same rigor that has been applied to studying outcomes needs to be applied to understanding how to change practice. This study offered one framework for how this can be done. Studying implementation was valuable for illuminating site capacities, variances and challenges. Continued study and sharing of implementation experiences can help support wider organizational uptake and also identify needed system supports (e.g., patient registry, incentive payments, accountability monitoring). Future research should combine research on the success of the implementation (number of patients reached, health outcomes, patient satisfaction) with information on how changes were implemented. Key issues to study are sustainability of practice change after initial implementation and how to support wider system spread. 


\section{References}

Balogh, R., Wood, J., Lunsky, Y., Isaacs, B., Ouellette-Kuntz, H., \& Sullivan, W. (2015). Effects of a continuing education course for primary care providers. Canadian Family Physician, 61(7), 316-323.

Blase, K., \& Fixsen, D. (2013). Stages of implementation analysis: Where are we? Chapel Hill, NC: National Implementation Research Network.

Bond, G. R., Drake, R. E., McHugo, G. J., Peterson, A. E., Jones, A. M., \& Williams, J. (2014). Long-term sustainability of evidence-based practices in community mental health agencies. Administration and Policy in Mental Health and Mental Health Services Research, 41(2), 228236.

Burnard, P., Gill, P., Stewart, K., Treasure, E., \& Chadwick, B. (2008). Analysing and presenting qualitative data. British Dental Journal, 204(8), 429-432. doi:10.1038/sj.bdj.2008.292

Buszewicz, M., Welch, C., Horsfall, L., Nazareth, I., Osborn, D., Hassiotis, A., ..., Strydom, A. (2014). Assessment of an incentivized scheme to provide annual health checks in primary care for adults with intellectual disability: a longitudinal cohort study. Lancet Psychiatry, 1(7), 522-530. doi:10.1016/S2215-0366(14)00079-0

Chauhan U., Kontopantelis, E., Campbell, s., Jarrett, H., \& Lester, H. (2010). Health checks in primary care for adults with intellectual disabilities: How extensive should they be? Journal of Intellectual Disability Research, 54(6), 479-486. doi:10.1111/j.1365-2788.2010.01263.x

Damschroder, L. J., Aron, D. C., Keith, R. E., Kirsh, S. R., Alexander, J. A., \& Lowery, J. C. (2009). Fostering implementation of health services research findings into practice: a consolidated framework for advancing implementation science. Implementation Science, 4, 50-50. doi:10.1186/1748-5908-4-50 
Developmental Disabilities Primary Care Initiative. Tools for the Primary Care of People with Developmental Disabilities. $1^{\text {st }}$ ed. [Removed for review]: MUMS Guideline Clearinghouse, 2011.

Elo, S., \& Kynga s, H. (2007). The qualitative content analysis process. Journal of Advanced Nursing, 62(1), 107-115. doi:10.1111/j.1365-2648.2007.04569.x

Fortney, J., Enderle, M., McDougall, S., Clothier, J., Otero, J., Altman, L., \& Curran, G. (2012). Implementation outcomes of evidence-based quality improvement for depression in VA community based outpatient clinics. Implementation Science, 7(30), 30-30. doi:10.1186/17485908-7-30

Greenhalgh, T., Robert G., Macfarlane, F., Bate, P., \& Kyriakidou, O. (2004). Diffusion of innovations in service organizations: Systematic review and recommendations. The Milbank Quarterly, 82(4), 581-629.

Health Quality Ontario. (2014). Key Observations 2014-15 Quality Improvement Plans Primary Care, Toronto.

Ketchum, A. M., Saleh, A. A., \& Jeong, K. (2011). Type of Evidence Behind Point-of-Care Clinical Information Products: A Bibliometric Analysis. Journal of Medical Internet Research, 13(1), e21. http://doi.org/10.2196/jmir.1539

Kirsh, S. R., Lawrence, R. H., \& Aron, D. C. (2008). Tailoring an intervention to the context and system redesign related to the intervention: a case study of implementing shared medical appointments for diabetes. Implementation Science, 3(1), 34-34. doi:10.1186/1748-5908-3-34

Lennox, N., Bain, C., Rey-Conde, T., Purdie, D., Bush, R., \& Pandeya, N. (2007). Effects of a comprehensive health assessment programme for Australian adults with intellectual disability: 
a cluster randomized trial. International Journal of Epidemiology, 36, 139-146.

doi:10.1093/ije/dyl254

Lennox, N. G., Brolan, C. E., Dean, J., Ware, R. S., Boyle, F. M., Gomez, M. T., ... \& Bain, C. (2013). General practitioners’ views on perceived and actual gains, benefits and barriers associated with the implementation of an Australian health assessment for people with intellectual disability. Journal of Intellectual Disability Research, 57(10), 913-922. doi:10.1111/j.1365-2788.2012.01586.x

Author citation. (YYYY).

Lunsky, Y., Klein-Geltink, J. E., \& Yates, E. A. (2013). Atlas on the Primary Care of Adults with Developmental Disabilities in [Removed for review]. Retrieved from https://www.porticonetwork.ca/documents/38160/99698/Atlas+revised+2014/c2d68a41-ed3d44dc-8a14-7f30e044c17e.

McConkey, R., Taggart, L., \& Kane, M. (2015). Optimizing the uptake of health checks for people with intellectual disabilities. Journal of Intellectual Disabilities, 1744629514568437.

Ouellette-Kuntz, H., Cobigo, V., Balogh, R., Wilton, A., \& Lunsky, Y. (2015). The uptake of secondary prevention by adults with intellectual and developmental disabilities. Journal of Applied Research in Intellectual Disabilities, 28(1), 43-54.Patton, M. Q., (2002). Qualitative research and evaluation methods. Thousand Oaks, Calif: Sage Publications.

Ovretveit, J. (2014). Evaluating improvement and implementation for health. Open University Press, New York.

Proctor, E., Silmere, H., Raghavan, R., Hovmand, P., Aarons, G., Bunger, A., ... Hensley, M. (2009). Outcomes for implementation research: Conceptual distinctions, measurement 
challenges, and research agenda. Administration and Policy in Mental Health and Mental Health Services Research, 38(2), 65-76. doi:10.1007/s10488-010-0319-7

Pronovost, P. J. (2013). Enhancing physicians' use of clinical guidelines. The Journal of American Medical Association, 310(23), 2501-2502. doi:10.1001/jama.2013.281334

Robertson, J., Hatton, C., Emerson, E., \& Baines S. (2014). The impact of health checks for people with intellectual disabilities: An updated systematic review of evidence. Research in Developmental Disabilities, 35(10), 2450-2462.

Russell, G. M., Dabrouge, S., Hogg, W., Geneau, R., Muldoon, L., \& Tuna, M. (2009). Managing chronic disease in [Removed for review] primary care: The impact of organizational factors. Annals of Family Medicine, 7(4), 309-318. doi:10.1370/afm.982

Rosser, W. W., Colwill, J. M., Kasperski, J., \& Wilson, L. (2011). Progress of [Removed for review] family health team model: A patient-centered medical home. Annals of Family Medicine, 9(2): 165-171. doi:10.1370/afm.1228

Rycroft-Malone, J. (2008). Evidence-informed practice: From individual to context. Journal of Nursing Management, 16(4), 404-408. doi:10.1111/j.1365-2834.2008.00859.x

Stein, B. D., Celedonia, K. L., Kogan, J. N., Swartz, H. A., \& Frank, E. (2013). Facilitators and barriers associated with implementation of evidence-based psychotherapy in community settings. Psychiatric Services, 64(12), 1263-1266.

Sullivan, W. F., Berg, J. M., Bradley, E., Cheetham, T., Denton, R., Heng, J., ... McMillan, S. (2011). Primary care of adults with developmental disabilities: Canadian consensus guidelines. Canadian Family Physician, 57(5), 541-553.

Torrey, W. C., Bond, G. R., McHugo, G. J., \& Swain, K. (2012). Evidence-based practice implementation in community mental health settings: the relative importance of key domains 
of implementation. Administration and Policy in Mental Health and Mental Health Services Research, 39, 353-364. doi:10.1007/s10488-011-0357-9

Walmsley, J. (2011). An investigation into the implementation of annual health checks for people with intellectual disabilities. Journal of Intellectual Disabilities, 15(3), 157-166. doi: $10.1177 / 1744629511423722$ 
Table 1

Contextual Features of Study Practices

\begin{tabular}{|c|c|c|}
\hline Contextual feature & Family Health Team 1 & Family Health Team 2 \\
\hline 1. Practice size and structure & $\begin{array}{l}\text { - Large urban center } \\
\text { - Multi-site } \\
\text { - } 70 \text { staff physicians, } 30 \text { receptionists } \\
\text { - 35,000 patients }\end{array}$ & $\begin{array}{l}\text { - Mid-size urban setting } \\
\text { - Single site } \\
\text { - } 25 \text { staff physicians, } 5 \text { receptionists } \\
\text { - } 15,000 \text { patients }\end{array}$ \\
\hline 2. Inter-professional team & $\begin{array}{l}\text { - Practice includes allied health staff } \\
\text { - Inter-professional care approaches still developing } \\
\text { - No specific programs for patients with IDD }\end{array}$ & $\begin{array}{l}\text { - Practice includes allied health staff } \\
\text { - Inter-professional care approaches still developing } \\
\text { - No specific programs for patients with IDD }\end{array}$ \\
\hline 3. EMR functionality & $\begin{array}{l}\text { - Functionality includes forms, alerts, clinical } \\
\text { information } \\
\text { - Includes some fillable forms tailored to care of } \\
\text { patients with IDD } \\
\text { - EMR has major role in standardizing practice across } \\
\text { multiple locations } \\
\end{array}$ & $\begin{array}{l}\text { - Functionality primarily includes fillable forms } \\
\text { - Includes a fillable form tailored to care of patients } \\
\text { with IDD } \\
\text { - Other web based tools are referenced by cannot } \\
\text { be accessed directly from the EMR }\end{array}$ \\
\hline $\begin{array}{l}\text { 4. Quality improvement } \\
\text { program }\end{array}$ & $\begin{array}{l}\text { - QI program in place } \\
\text { - Health Check project not on QI agenda } \\
\text { - No resources available for implementation through } \\
\text { QI program }\end{array}$ & $\begin{array}{l}\text { - QI program in place } \\
\text { - Health Check project not on QI agenda (at start of } \\
\text { project) } \\
\text { - No resources available for implementation through } \\
\text { QI program }\end{array}$ \\
\hline $\begin{array}{l}\text { 5. Academic affiliation } \\
\text { (training and research } \\
\text { roles) }\end{array}$ & $\begin{array}{l}\text { - One of multiple (12) training sites for Department of } \\
\text { Family Medicine } \\
\text { - Care for persons with IDD not a specific } \\
\text { Department of Family Medicine focus } \\
\text { - No remunerated academic time for HC } \\
\text { implementation }\end{array}$ & $\begin{array}{l}\text { - Main teaching practice for the Department of } \\
\text { Family Medicine } \\
\text { - Care for persons with IDD is clinical and academic } \\
\text { interest } \\
\text { - Lead physician had some remunerated academic } \\
\text { time for implementation } \\
\text { - Some research assistant support available }\end{array}$ \\
\hline 6. Practice foci & $\begin{array}{l}\text { - Vulnerable populations are practice focus (e.g., } \\
\text { persons who are homeless, low income, recent } \\
\text { immigrants, with HIV) } \\
\text { - Pockets of IDD expertise }\end{array}$ & $\begin{array}{l}\text { - Care of adults with IDD is one practice focus } \\
\text { - Several physicians have advanced training and } \\
\text { expertise }\end{array}$ \\
\hline
\end{tabular}


Table 2

Health Check Implementation by Study Practices and Contextual Influences

\begin{tabular}{|c|c|c|c|}
\hline \multirow{2}{*}{$\begin{array}{l}\text { Core Health Check } \\
\text { Components }\end{array}$} & \multicolumn{2}{|c|}{ Implementation Strategies } & \multirow{2}{*}{ Key Contextual Influences } \\
\hline & $\begin{array}{l}\text { FHT 1:Multiple } \\
\text { clinical sites }\end{array}$ & FHT 2:One clinic site & \\
\hline $\begin{array}{l}\text { 1. Identification of } \\
\text { patients with IDD in } \\
\text { the practice }\end{array}$ & \multicolumn{2}{|c|}{$\begin{array}{l}\text { - EMR search for patients with IDD (key word } \\
\text { search at FHT } 1 \text { and ICD codes at FHT 2) } \\
\text { - Manual staff review for corrections, additions }\end{array}$} & $\begin{array}{l}\text { Practice size and structure: } \\
\text { For FHT } 1 \text { the manual staff review component was more } \\
\text { complex and time consuming due to staff dispersal across } \\
\text { multiple sites } \\
\text { EMR functionality: } \\
-\quad \text { Both sites had no existing registry of patients with IDD } \\
\text { Both sites used the EMR to identify patients } \\
\text { QI program: } \\
\text { Both sites did not have protected time for IT work through QI } \\
\text { program, leading to delaying in search completion }\end{array}$ \\
\hline $\begin{array}{l}\text { 2. Invitation to } \\
\text { participate in } \mathrm{HC}\end{array}$ & $\begin{array}{l}\text { - Designated to } 1 \\
\text { clerical staff for all } \\
\text { invitational phone } \\
\text { calls } \\
\text { - Patients were } \\
\text { referred to local site } \\
\text { for appointment } \\
\text { booking } \\
\text { - Use of standardized } \\
\text { invitation script } \\
\text { - } 2 \text { reminder phone } \\
\text { calls for patients } \\
\text { - Physician alert - } \\
\text { embedded in EMR }\end{array}$ & $\begin{array}{l}\text { - Designated to } 1 \\
\text { clerical staff for all } \\
\text { invitational phone calls } \\
\text { and for the } \\
\text { appointment booking } \\
\\
\text { - Use of standardized } \\
\text { script } \\
\text { - } 1 \text { reminder phone call } \\
\text { for patients } \\
\text { - Physician alert - email } \\
\text { message by clerical }\end{array}$ & $\begin{array}{l}\text { Practice size and structure: } \\
\text { For FHT 1- complex to coordinate phone calls across many } \\
\text { clerical staff at multiple sites } \\
\text { QI program: } \\
\text { For both sites, the QI program was not a formal route for } \\
\text { securing clerical time since the health check was not in } \\
\text { program } \\
\text { Practice foci: } \\
\text { FHT 1 - patients with IDD not practice focus; site } \\
\text { experienced delays getting access to implementation } \\
\text { supports; ultimately secured a modest amount of clerical time } \\
\text { FHT 2- having patients with IDD as practice focus may } \\
\text { account for some access to clerical staff time for this work }\end{array}$ \\
\hline $\begin{array}{l}\text { 3. Training/ education } \\
\text { for staff }\end{array}$ & $\begin{array}{l}\text { - Staff meetings } \\
\text { - Point of care } \\
\text { clinical tools and } \\
\text { prompts embedded }\end{array}$ & $\begin{array}{l}\text { - Staff } \\
\text { rounds/meetings } \\
\text { - Resident } \\
\text { curriculum }\end{array}$ & $\begin{array}{l}\text { EMR functionality: } \\
\text { For FHT 1- staff were accustomed to using EMR based tools } \\
\text { to support clinical care and some tools for care of patients } \\
\text { with IDD were already available in the EMR }\end{array}$ \\
\hline
\end{tabular}




\begin{tabular}{|c|c|c|c|}
\hline & $\begin{array}{l}\text { in EMR, tailored to } \\
\text { care of patients } \\
\text { with IDD }\end{array}$ & enhancement & 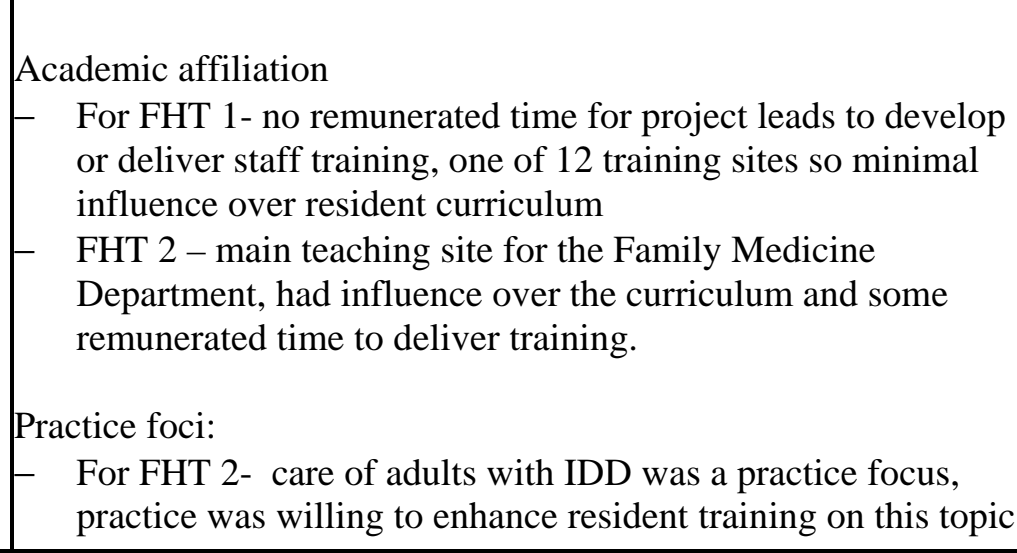 \\
\hline 4. Health check exam & $\begin{array}{l}\text { - Conducted by staff } \\
\text { physician, nurse } \\
\text { practitioner or } \\
\text { resident (similar to } \\
\text { all practice patients) } \\
\text { - Allied health staff } \\
\text { not consistently } \\
\text { involved }\end{array}$ & $\begin{array}{l}\text { - Conducted } \\
\text { primarily by } \\
\text { residents supervised } \\
\text { by faculty } \\
\text { physicians as an } \\
\text { expected part of } \\
\text { their curriculum } \\
\text { - Allied health staff } \\
\text { not consistently } \\
\text { involved }\end{array}$ & $\begin{array}{l}\text { Inter-professional care: } \\
-\quad \text { Both sites are still developing inter-professional care } \\
\text { approaches, currently no structured program is available } \\
\text { Academic affiliation and practice foci: } \\
-\quad \text { For FHT } 2 \text { - care of patients with IDD was practice focus and } \\
\text { main teaching practice for Department of Family Medicine; } \\
\text { all residents were expected to conduct a health check as part } \\
\text { of their clinic rotation }\end{array}$ \\
\hline
\end{tabular}

